Reprod. Nutr. Dévelop., 1987, 27 (1 B), 283-284.

\title{
Possibilités de complémentation de la paille par du sérum de luzerne
}

J. L. TISSERAND, F. MESCHY, Catherine CORDELET, F. FAURIE, J. MAZOLLIER

Laboratoire de recherches de la Chaire de Zootechnie E.N.S.S.A.A., I.N.R.A., 26, bd Docteur Petijean, 21100 Dijon, France.

Summary. The addition of lucerne serum to barley and wheat straw increased total forage digestibility by about $20 \%$; this was comparable to the result obtained by the addition of molasses and urea. The digestibilities of the organic matter and Weende's cellulose (table 1) increased equally as the lucerne serum contained no substance, like $2 \%$ ensipron, which would reduce the cellulolytic activity of rumen micro-organisms.

L'extraction des protéines de luzerne pour l'alimentation des monogastriques laisse un sous-produit, le sérum ( $45 \%$ de matière sèche) qui, riche en matières azotées (23\% de la MS), est susceptible de complémenter la paille. C'est pourquoi, en l'absence de toute information sur cette possibilité, nous avons réalisé deux essais pour connaître la valeur alimentaire d'une paille d'orge ou de blé additionnée de sérum de luzerne ou de mélasse + urée par comparaison à la paille témoin.

Matériel et méthodes. La paille d'orge $(\% \mathrm{MS}=$ matières minérales 3,4 ; cellulose brute 45,9 et matières azotées 3,5 ) et la paille de blé (\% MS = matières minérales 6,1 ; cellulose brute 42,6 et matières azotées 2,6 ) sont utilisées seules ou additionnées soit de mélasse + urée $(200 \mathrm{~g}$ et $10 \mathrm{~g}$ respectivement par $\mathrm{kg}$ ) soit de sérum de luzerne $(200 \mathrm{~g} / \mathrm{kg})$ (Meschy, 1984 ; Mazollier, 1984).

Les rations expérimentales sont composées de ces fourrages distribués à volonté ( $10 \%$ refus) avec du tourteau de soja ( $150 \mathrm{~g}$ par $\mathrm{kg}$ de paille seule et 100 et $75 \mathrm{~g}$ par $\mathrm{kg}$ de paille complémentée respectivement pour les pailles d'orge et de blél pendant 30 jours consécutifs à 6 béliers mâles castrés maintenus en cage à bilan. Durant les dix derniers jours de chaque période, l'ingestibilité et la digestibilité des rations sont mesurées (Meschy, 1984). Par ailleurs, les mêmes régimes sont distribués à 3 béliers munis d'une canule permanente du rumen pour étudier l'activité cellulolytique en mesurant la dégradation de la lignocellulose (ADF) de la paille durant $48 \mathrm{~h}$ in sacco (12 résultats par paille). Le sérum de luzerne est conservé par addition d'ensipron (mélange $2 / 3$ acide formique, $1 / 3$ formol) ; le taux de $1 \%$ paraissant insuffisant dans le premier essai a été porté à $2 \%$ dans le second.

Résultats et discussion. En tenant compte de l'apport de sérum de luzerne, il apparaît que l'addition de ce produit augmente d'environ $15 \%$ l'ingestion de la paille d'orge mais est pratiquement sans effet pour la paille de blé. Ces résultats sont comparables à ceux observés avec l'addition de mélasse + urée pour la paille d'orge (tabl. 1). La digestibilité de la matière organique est améliorée d'environ $15 \%$ par l'addition de mélasse + urée ou de sérum de luzerne mais, dans ce dernier cas, uniquement avec la paille d'orge. En ce qui concerne la digestibilité de la cellulose brute, si elle est augmentée de 10 à $20 \%$ avec l'addition de mélasse + urée, il n'en est pas de même avec le sérum de luzerne qui n'améliore pratiquement pas la digestibilité des parois de la paille d'orge et diminue celle de 
la paille de blé. Toutefois, il paraît probable que cet effet dépressif soit imputable à l'addition de $2 \%$ d'ensipron au sérum de luzerne. Ceci est confirmé par les valeurs observées pour l'activité cellulolytique avec la ration paille de blé additionnée de sérum de luzerne conservé avec $2 \%$ d'ensipron (tabl. 1). L'apport d'énergie de la paille évalué par la matière organique digestible ingérée ad libitum est amélioré par addition de sérum de luzerne (notamment conservé avec $1 \%$ d'ensipron). II ne nous paraît pas possible de tirer des conclusions des résultats obtenus en matière d'utilisation de la matière azotée car il ne nous a pas été possible d'avoir des taux de matière azotée et surtout des ingestions comparables entre régimes. De plus, la proportion de matière azotée de tourteau est très variable d'un régime à l'autre. Toutefois, les résultats constatés pour le régime paille de blé plus sérum de luzerne à $2 \%$ d'ensipron confirment l'effet dépressif du formol.

TABL. 1. - Ingestibilité, digestibilité et effet sur l'activité cellulolytique de la paille seule (P) ou additionnée de sérum de luzerne (P.S.L.) ou de mélasse + urée (P.M.U.) (valeur \pm écart-type).

\begin{tabular}{|c|c|c|c|c|c|c|}
\hline & \multicolumn{3}{|c|}{ Essai 1 Paille d'orge } & \multicolumn{3}{|c|}{ Essai 2 Paille de blé } \\
\hline & $\mathbf{P}$ & P.S.L. & P.M.U. & $P$ & P.S.L. & P.M.U. \\
\hline $\begin{array}{l}\text { M.S. ingérée (paille }+ \text { supplé- } \\
\text { ment) g MS } / \mathrm{kg} \mathrm{P0,75}\end{array}$ & $42,1 \pm 2,0$ & $59,5 \pm 6,6$ & $55,6 \pm 6,1$ & $38,8 \pm 4,8$ & $44,1 \pm 5,3$ & $47,0 \pm 5,4$ \\
\hline $\begin{array}{l}\text { Matière organique digestible } \\
\text { ingérée } \mathrm{g} / \mathrm{kg} P^{0,75}\end{array}$ & 18,8 & 29,6 & 28,9 & 16,2 & 18,2 & 21,8 \\
\hline $\begin{array}{l}\text { M.A.T. \% M.S. (ration) } \\
\text { M.A.T. ingérée g/j } \\
\text { Digestibilite : }\end{array}$ & $\begin{array}{l}10,9 \\
96,0\end{array}$ & $\begin{array}{r}11,9 \\
130,7\end{array}$ & $\begin{array}{r}12,5 \\
126,9\end{array}$ & $\begin{array}{r}9,9 \\
91,1\end{array}$ & $\begin{array}{r}8,6 \\
71,3\end{array}$ & $\begin{array}{r}11,7 \\
109,9\end{array}$ \\
\hline $\begin{array}{l}\text { Matière organique } \\
\text { Cellulose brute } \\
\text { Matière azotée }\end{array}$ & $\begin{array}{l}46,7 \pm 2,7 \\
56,0 \pm 1,9 \\
59,8+19\end{array}$ & $\begin{array}{l}53,7 \pm 2,9 \\
57,3 \pm 6,6 \\
64,4+4,8\end{array}$ & $\begin{array}{l}54,7 \pm 1,4 \\
61,3 \pm 2,1 \\
64,4+2,4\end{array}$ & $\begin{array}{l}44,2 \pm 3,1 \\
43,5 \pm 3,0 \\
68,8+3,3\end{array}$ & $\begin{array}{l}44,7 \pm 3,3 \\
39,9 \pm 3,7 \\
54,3+2,3\end{array}$ & $\begin{array}{l}50,4 \pm 1,6 \\
52,7 \pm 1,4 \\
68,8+2,1\end{array}$ \\
\hline $\begin{array}{l}\text { Activité cellulolytique (ADF } \\
\text { dégradé } \% \text { ) }\end{array}$ & $44,5 \pm 2,6$ & $50,1 \pm 3,5$ & $50,3 \pm 3,1$ & $33,1 \pm 1,3$ & $38,6 \pm 1,9$ & $48,8 \pm 3,0$ \\
\hline
\end{tabular}

En conclusion, l'addition de sérum de luzerne au taux de $20 \%$ augmente l'apport énergétique de la paille distribuée à volonté aux animaux. Les résultats obtenus s'avèrent comparables à ceux observés avec une addition de mélasse $20 \%$ et d'urée $1 \%$. Il conviendrait toutefois, avant de préconiser un tel traitement, de préciser les conditions de conservation du sérum de luzerne.

Mazollier J., 1984. Etude de l'amélioration de la valeur nutritive des pailles par des complémentations E.N.S.B.A.N.A., Univ. Dijon.

Meschy F., 1984. Th. Doct.-Ing. Nutrition-Alimentation, Univ. Dijon. 